Article

\title{
Key Performance Indicators for an Energy Community Based on Sustainable Technologies
}

\author{
Giovanni Bianco $^{1}\left(\mathbb{D}\right.$, Barbara Bonvini ${ }^{2}$, Stefano Bracco ${ }^{1, *(\mathbb{D})}$, Federico Delfino ${ }^{1}$, Paola Laiolo ${ }^{2}$ \\ and Giorgio Piazza ${ }^{1}$ (D)
}

1 DITEN_Electrical, Electronics and Telecommunication Engineering and Naval Architecture Department, University of Genoa, 16145 Genova, Italy; giovanni.bianco@edu.unige.it (G.B.); federico.delfino@unige.it (F.D.); giorgio.piazza@edu.unige.it (G.P.)

2 CenVIS-Service Centre for the Management of Ventimiglia, Imperia and Savona Campuses of the University of Genoa, University of Genoa, 17100 Savona, Italy; barbara@studiotecnicobonvini.it (B.B.); paola.laiolo@unige.it (P.L.)

* Correspondence: stefano.bracco@unige.it; Tel.: +39-01921945123

Citation: Bianco, G.; Bonvini, B.; Bracco, S.; Delfino, F.; Laiolo, P.; Piazza, G. Key Performance Indicators for an Energy Community Based on Sustainable Technologies. Sustainability 2021, 13, 8789. https:// doi.org/10.3390/su13168789

Academic Editor: Alberto-Jesus Perea-Moreno

Received: 29 June 2021

Accepted: 3 August 2021

Published: 6 August 2021

Publisher's Note: MDPI stays neutral with regard to jurisdictional claims in published maps and institutional affiliations.

Copyright: (c) 2021 by the authors. Licensee MDPI, Basel, Switzerland. This article is an open access article distributed under the terms and conditions of the Creative Commons Attribution (CC BY) license (https:// creativecommons.org/licenses/by/ $4.0 /)$.

\begin{abstract}
As reported in the "Clean energy for all Europeans package" set by the EU, a sustainable transition from fossil fuels towards cleaner energy is necessary to improve the quality of life of citizens and the livability in cities. The exploitation of renewable sources, the improvement of energy performance in buildings and the need for cutting-edge national energy and climate plans represent important and urgent topics to be faced in order to implement the sustainability concept in urban areas. In addition, the spread of polygeneration microgrids and the recent development of energy communities enable a massive installation of renewable power plants, high-performance small-size cogeneration units, and electrical storage systems; moreover, properly designed local energy production systems make it possible to optimize the exploitation of green energy sources and reduce both energy supply costs and emissions. In the present paper, a set of key performance indicators is introduced in order to evaluate and compare different energy communities both from a technical and environmental point of view. The proposed methodology was used in order to assess and compare two sites characterized by the presence of sustainable energy infrastructures: the Savona Campus of the University of Genoa in Italy, where a polygeneration microgrid has been in operation since 2014 and new technologies will be installed in the near future, and the SPEED2030 District, an urban area near the Campus where renewable energy power plants (solar and wind), cogeneration units fed by hydrogen and storage systems are planned to be installed.
\end{abstract}

Keywords: microgrid; renewable energy; sustainable energy; energy efficiency; energy community; photovoltaics; wind; storage; hydrogen

\section{Introduction}

In 2015, the UN Member States adopted the 2030 Agenda for Sustainable Development, pursuing the commitment to tackle worldwide climate change by 2030 with the application of 17 Sustainable Development Goals (SDGs) [1]. These goals aim to strengthen public awareness to take action against the degradation of the planet, guarantee economic growth and reduce social inequalities through strong and global cooperation from both public and private stakeholders [2,3]. Global warming is threatening our climate system and causing irreversible consequences. The reduction of greenhouse gas (GHG) emissions into the atmosphere has become a very urgent issue to be faced in order to guarantee a more sustainable future [4]. Now more than ever, the energy transition towards sustainable systems is considered one of the main drivers to implement important climate actions $[5,6]$. This awareness has been strengthened by the European Green Deal, with the ambitious plan to achieve a Carbon Neutral EU by 2050 [7]. 
Since most GHGs are produced by the energy and transport sectors [8], it is necessary to implement sustainable and efficient systems for energy production together with green transportation. The increasing integration of Renewable Energy Sources (RESs) into the traditional power systems led, almost 20 years ago, to the origin of the microgrid concept [9]. A microgrid can be defined as an aggregation of small-scale generating units (from renewable or traditional sources), loads and storage systems (electrical and thermal) related to a restricted area and managed by an energy management system. Currently, different applications at different scales can be found, including at the residential/building, commercial/industrial, military, campus and community levels [10-14]. While the first category refers to small-scale systems, the other types indicate microgrids at a larger scale. In campuses, a microgrid permits to share energy across different buildings, providing self-produced power (usually generated by means of RESs) to reduce the power withdrawn from the distribution grid. At the community level, different microgrids can interact to accomplish integrated operations aimed to reduce costs and to improve the resilience of the overall system. Due to their "cross-sectoral" research, their international approach and their partnerships with public-private institutions, universities can play an active role in facilitating the deployment of distributed generation technologies and microgrids, and more generally, in the achievement of the aforementioned SDGs [15,16]. In addition to education and research, the so-called "third mission" encourages academic staff to work toward the improvement of people's lives, contributing to the growth of a sustainable society and the development of economic systems. Universities can test at the campus level new facilities and methods through Living Labs (LLs) and open-innovation environments used as pilot sites for urban applications [17-19].

To achieve significant results (such as those of the SDGs) some stakeholders adopt systematic approaches, and a well-established method is based on the definition of Key Performance Indicators (KPIs) to formally evaluate the outcomes of newly implemented policies and strategies. Environmental and energy-based KPIs are frequently chosen to give a neutral assessment of projects in the field of smart grid or smart district upgrades [20]. KPIs can be expressed either as absolute values (i.e., energy production from renewables, carbon dioxide emissions, etc.) or as percentage values calculated with respect to a reference scenario (i.e., carbon dioxide reduction, increase of the renewable share in the energy mix, etc.). They can be used to define high level goals (related to national and international energy visions) as well as local targets in the case of microgrids and energy communities [21]. Many authors suggest the use of KPIs in the design phase of a microgrid, as in [22], where energy consumption savings and emission reductions are highlighted. In [23] the authors monitor the development of a smart grid in Malaga and the achievement of environmental goals through a set of KPIs based on field measurements, whereas in [24] two specific indicators (namely self-consumption and self-sufficiency indexes) are employed for the optimal sizing of a photovoltaic plant, coupled with a storage system, within an energy community. Regarding smart districts, many KPI-based approaches are present in the literature. In [25] Y. Li et al. developed a multi-level KPI structure based on three different hierarchy layers—strategic, tactical and operational—with the advantage of distributing the KPIs among the different stakeholders of the system while maintaining their interdependence. In [26] KPIs specifically defined for a smart campus are described; in particular, several environmental KPIs with regard to GHG emissions and electric mobility penetration within the monitored system are presented. In [27] the authors define KPIs for a Zero Emissions Neighborhood (ZEN), considering indicators for seven macro-fields: energy, GHG emissions, power/loads, mobility, economy, spatial quality and innovation. Angelakoglou et al. [28] formalize six dimensions of KPIs to assess smart city solutions, considering technical, ICT, environmental, economic, social and legal aspects. In [29] the authors define environmental and energy KPIs to investigate and compare the sustainable growth of several cities around the world, assigning a score from 1 to 10 to rank the different locations. Moreover, in the literature, environmental and economic KPIs to support strategic investment decisions in the microgrid field are also evaluated [30-32]. 
Finally, in [33] the authors focus their attention on the use of social indicators, such as job creation and social acceptance, to best design hybrid renewable energy systems.

This paper introduces an appropriate set of key performance indicators (KPIs) to establish a common framework to assess and compare different energy communities (e.g., smart energy districts and zero emissions neighborhoods), taking into account technical and environmental aspects. The proposed methodology has been used to evaluate two neighboring sites: the Savona Campus of the University of Genova (in the present configuration and in the upcoming one, called Savona Campus 2.0) and the SPEED2030 District. Although the two presented case studies are close in geographical position, they were designed at different times, and thus they face the shared energy supply problem in very different ways. For this reason, KPIs constitute a significant tool to underline the similarities and discrepancies of the two approaches.

In this paper we intend to deal with the expansion of the Savona Campus through the creation of a new real energy district (SPEED2030) that can also be used for research purposes. The main idea is to replicate the concept of the "smart polygeneration microgrid" by evaluating the application of different technologies such as heat pumps, wind turbines, and Hydrogen CHP systems, combined with those already used, such as PV plants and battery energy storage. Due to the large investment and operating costs involved in such a project, at the preliminary stages it is necessary to evaluate the best technologies to use and then determine their optimal size. While the size of technologies can be decided using, for example, optimal planning studies, the choice of one technology over another can be made with reference to different and wider criteria. In this paper we adopted some KPI indexes to drive the choice of the technologies for the new district by comparing it with the existing one. In our opinion, the real case study reported in the paper can provide useful information to research groups who aim to create similar innovative research infrastructures.

The paper is organized as follows. In Section 2, the proposed methodology is presented and the defined key performance indicators are reported, while in Section 3, the smart energy infrastructures of the Savona Campus and the SPEED2030 District are described. In Section 4, the methodology is applied to the two aforementioned case studies, and the most significant results of the analysis are shown. In Section 5, conclusions are presented.

\section{Methodology and Definition of KPIs}

As already mentioned, key performance indicators could represent a common framework to evaluate different sites from energy and environmental points of view. Considering the complexity represented by energy communities, which could assume the role of polygeneration systems involving several primary energy sources, different energy vectors and different stages of conversion of the energy, the defined KPIs must be a good tradeoff between specificity of representation and application versatility. In the following section, three main groups of KPIs are defined in order to assess a specific site from a technical and environmental point of view:

- KPIs that evaluate the electrical performance of the site;

- KPIs that evaluate the thermal performance of the site;

- KPIs that assess the environmental impact of the site.

The following three KPIs evaluate the electrical performance: the overall Electrical SelfProduction (ESP) is defined in Equation (1), the Electrical Self-Production from Renewable Energy Sources (ESPRES) is reported in Equation (2), while the Electrical Self-Production from Combined Heat and Power (ESPCHP) is defined in Equation (3).

$$
\begin{gathered}
E S P=\frac{E_{t o t}^{e l, s p}}{D_{t o t}^{e l}} \\
\text { ESPRES }=\frac{E_{r e s}^{e l, s p}}{E_{t o t}^{e l, s p}}
\end{gathered}
$$




$$
E S P C H P=\frac{E_{c h p}^{e l, s p}}{E_{t o t}^{e l, s p}}
$$

where $E_{t o t}^{e l, s p}$ is the overall electrical energy self-produced in the site, $D_{t o t}^{e l}$ is the overall electrical demand, $E_{r e s}^{e l, s p}$ is the amount of the self-produced energy from RES, and $E_{c h p}^{e l, s p}$ is the electrical energy produced by CHP technologies. All quantities are typically calculated on a yearly basis.

The next five KPIs consider either the thermal performance or the combined electri$\mathrm{cal} /$ thermal performance of the site. More precisely, the thermal KPIs define the following quantities: the share of Thermal energy produced by means of electric Boilers $(T B)$ is evaluated using Equation (4), the fraction of Thermal energy produced with CHP (TCHP) units is defined in Equation (5), the fraction of Thermal energy produced by means of Heat Pumps (THP) is reported in Equation (6) and the share of Thermal energy produced by RES (TRES) is shown in Equation (7).

$$
\begin{gathered}
T B=\frac{E_{b}^{t h, s p}}{E_{t o t}^{t h, s p}} \\
T C H P=\frac{E_{c h p}^{t h, s p}}{E_{t o t}^{t h, s p}} \\
T H P=\frac{E_{h p}^{t h, s p}}{E_{t o t}^{t h, s p}} \\
T R E S=\frac{E_{r e s}^{t h, s p}}{E_{t o t}^{t h, s p}}
\end{gathered}
$$

where $E_{\text {tot }}^{t h, s p}$ is the overall thermal energy produced in the site, $E_{b}^{t h, s p}$ is the thermal energy production of boilers, $E_{c h p}^{t h, s p}$ is the thermal production of the CHP units, $E_{h p}^{t h, s p}$ is the thermal energy generated by means of heat pumps and $E_{\text {res }}^{t h, s p}$ is the thermal energy coming from RES.

The Global Self-Production from CHP (GSPCHP) indicator is defined in Equation (8).

$$
G S P C H P=\frac{E_{c h p}^{e l, s p}+E_{c h p}^{t h, s p}}{D_{t o t}^{e l}+E_{t o t}^{t h, s p}}
$$

Finally, the last three indicators, reported in Equations (9)-(11), quantify the environmental impact in terms of tons per year of avoided $\mathrm{CO}_{2}\left(E C \mathrm{O}_{2}\right), \mathrm{NO}_{\mathrm{x}}\left(E N O_{x}\right)$ and $\mathrm{SO}_{2}\left(E S \mathrm{O}_{2}\right)$ with respect to the emissions associated with an equivalent site supplied by traditional energy sources, where the electrical demand is entirely satisfied by electricity from the national grid, the thermal demand is covered by traditional boilers and the cooling demand is satisfied by compression chillers.

$$
\begin{aligned}
& E C O_{2}=\frac{\Delta C O_{2}^{\text {site }}}{C O_{2}^{\text {site,tr }}} \\
& E N O_{x}=\frac{\Delta N O_{x}^{\text {site }}}{N O_{x}^{\text {site, } t r}} \\
& E S O_{2}=\frac{\Delta S O_{2}^{\text {site }}}{S O_{2}^{\text {site,tr }}}
\end{aligned}
$$




\section{Case Study}

Two smart energy sites have been compared through application of the proposed KPI approach: the Savona Campus of the University of Genoa in Italy [34] and the Savona Positive Energy \& Environment District (SPEED2030), which is a smart energy district pilot site very close to the Savona Campus that is still at the planning stage [35].

\subsection{Savona Campus of the University of Genoa}

The Savona Campus is a compound in the Legino neighborhood, two kilometers from the Savona city center; in the past, this location housed barracks [34]. The project of transforming the old Bligny Military Compound, dating back to the 1930s, to a University Campus was first conceived in 1990, as a joint initiative of the University of Genoa and local stakeholders. Today, the Campus hosts research laboratories of the University, research centers and SMEs. In the last decade, the "Energia 2020" project was developed at the Savona Campus [36-40]. It represents an important R\&D project related to the concepts of Sustainable Energy (renewable energy, energy saving and reduction of $\mathrm{CO}_{2}$ emissions) and the Smart City. The "Energia 2020" project, which was developed thanks to full public financing, was conceived to install, within the Savona Campus, innovative energy systems aimed at reducing operating costs and pollutant emissions, while at the same time creating a comfortable working environment for Campus users. In particular, the project consists of two main subprojects: Smart Polygeneration Microgrid (SPM) and Smart Energy Building (SEB). The Smart Polygeneration Microgrid (SPM) is a three-phase low-voltage (400 V line-to-line) "intelligent" distribution system, coupled with a thermal network composed of electrical/thermal loads and generation units [36]. The SPM electrical grid topology, as shown in Figure 1, is that of a ring (600 $\mathrm{m}$ long) with one main switchboard (QGEN) and five other switchboards (Q01, Q02, Q03, Q04 and Q05), to which the power plants and the loads are connected. A dedicated MV/LV transformer, linked to the MV busbar of the Savona Campus MV/LV substation, connects the SPM to the $15 \mathrm{kV}$ distribution network. The SEB is an environmentally sustainable building connected to the SPM as a "prosumer", equipped with renewable power plants and characterized by energy efficiency measures (high-performance thermal insulation materials and ventilated facades).

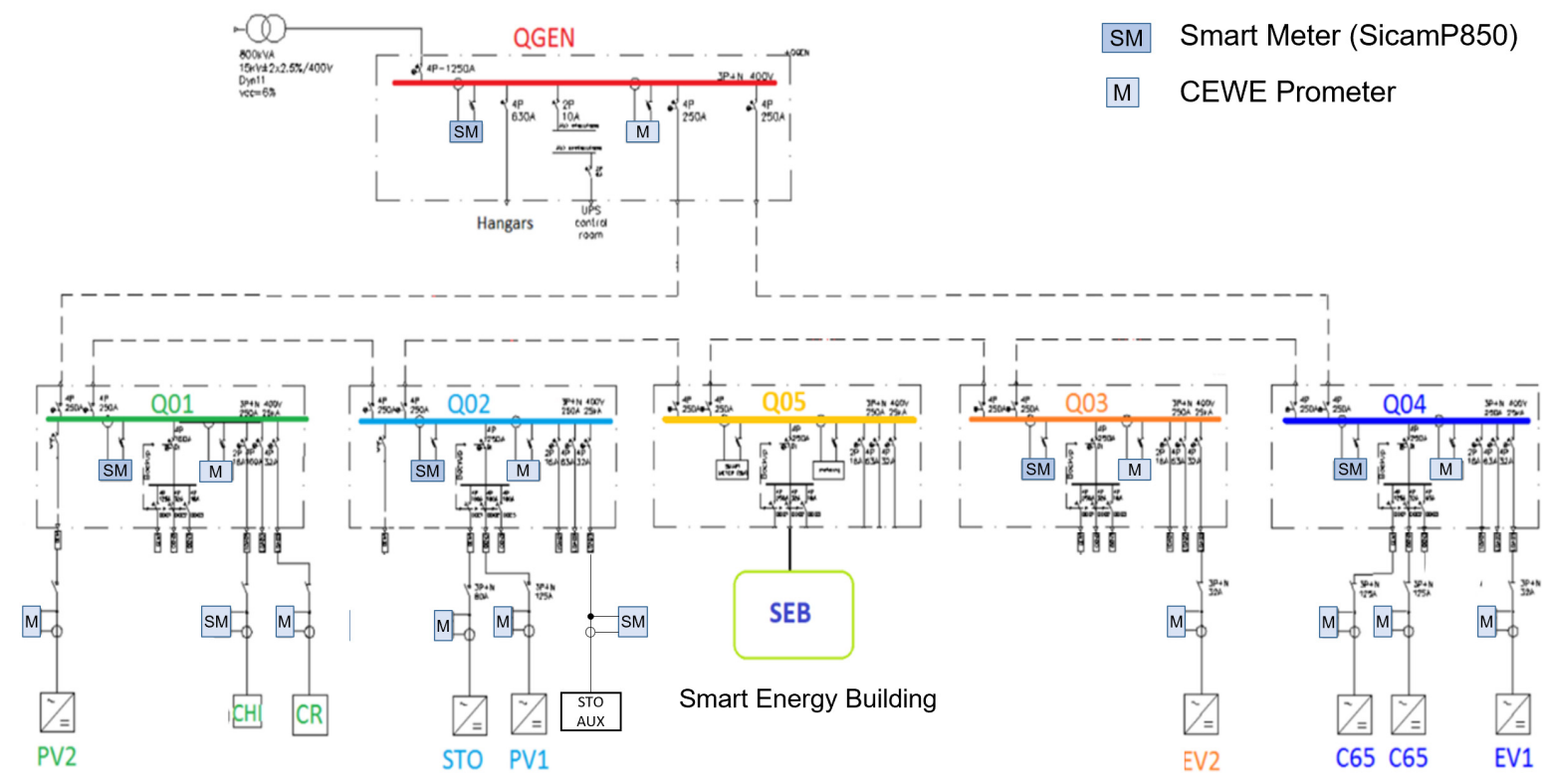

Figure 1. The single line wiring diagram of the Smart Polygeneration Microgrid (SPM).

As shown in Figure 1, in the SPM, the electrical energy is produced by two cogeneration microturbines (Capstone C65) and two photovoltaic fields (PV1 and PV2, $95 \mathrm{~kW}$ ). There are also storage systems (salt batteries STO1, $141 \mathrm{kWh}$ ), which are used to store 
surplus production coming from both the PV plants and the cogeneration units. The heating demand of the Campus is satisfied by the aforementioned microturbines (112 kW) and by two boilers $(900 \mathrm{~kW})$, all fed by natural gas. To cover the cooling needs, most of the buildings are equipped with dedicated compression chillers, and only two buildings are cooled by two absorption chillers $(220 \mathrm{~kW})$, thermally fed by the two microturbines. Underground pipelines convey the warm water from the thermal station (where the boilers and microturbines are located) to the different buildings for heating purposes; there is not a cooling network, since each building has a dedicated air-conditioning system. As far as electric mobility is concerned, there are three EV charging stations connected to the SPM: two are quick AC charging stations (EV1 and EV2, $22 \mathrm{~kW}$ ) and one is of the vehicle-to-grid (V2G) type (EV3, $15 \mathrm{~kW})$ [41].

The SPM is controlled and managed by a three-level system composed of smart meters and local automation devices; a SCADA (Supervisory Control And Data Acquisition) system based on two different software tools, for the electrical (SIMATIC WinCC) and thermal parts (DESIGO), respectively; and an Energy Management System (EMS) [36]. Two sets of power meters are installed in the SPM: non-fiscal power meters, for data acquisition and supervision, and fiscal energy meters, installed to measure the energy produced by each generation unit and the energy absorbed by the loads connected to each bus bar of the SPM. Some devices directly communicate using the IEC 61850 protocol, while others need the adoption of Remote Terminal Units (RTUs) to convert modbus signals into IEC 61850. The EMS is based on an MILP (mixed-integer linear programming) model, which aims to determine the daily optimal scheduling of cogeneration units, boilers and storage systems, with the goal of minimizing operating costs and emissions.

In the SEB, shown in Figure 2, the heating and cooling system is based on the exploitation of the geothermal source by a heat pump having a $45 \mathrm{~kW}$ rated thermal power coupled with eight borehole heat exchangers [36,38]. The building is also equipped with an air source heat pump (11.5 kW) and two vacuum tube solar collectors (Kloben Sky Pro 10 advanced type) for the production of domestic hot water, while an air-handling unit (21 $\mathrm{kW}$ rated thermal power) controls the air quality in each room of the building. As far as electrical production is concerned, a photovoltaic field $(21 \mathrm{~kW})$ is installed on the roof of the building, which can also exchange power with the SPM. The main electrical loads of the SEB are represented by LED lamps, office workstations, auxiliary systems of electrical/thermal power plants and fitness equipment in the gym located at the ground floor of the building. In the gym, there are also elliptical machines and bikes that convert human energy into electricity. A vehicle-to-building (V2B) station for electric vehicles is installed inside the building [41]; it is equipped with a CHAdeMO socket and is characterized by a maximum charging/discharging power of $15 \mathrm{~kW}$. The SEB is managed by a Building Management System (BMS) that interacts with the EMS of the SPM; therefore, thermal/electrical generation units and loads of the building are monitored and managed in real time in order to reduce the whole energy expense and the carbon footprint of the Campus. Furthermore, different indoor comfort levels can be set by the BMS to control the energy demand of the building.
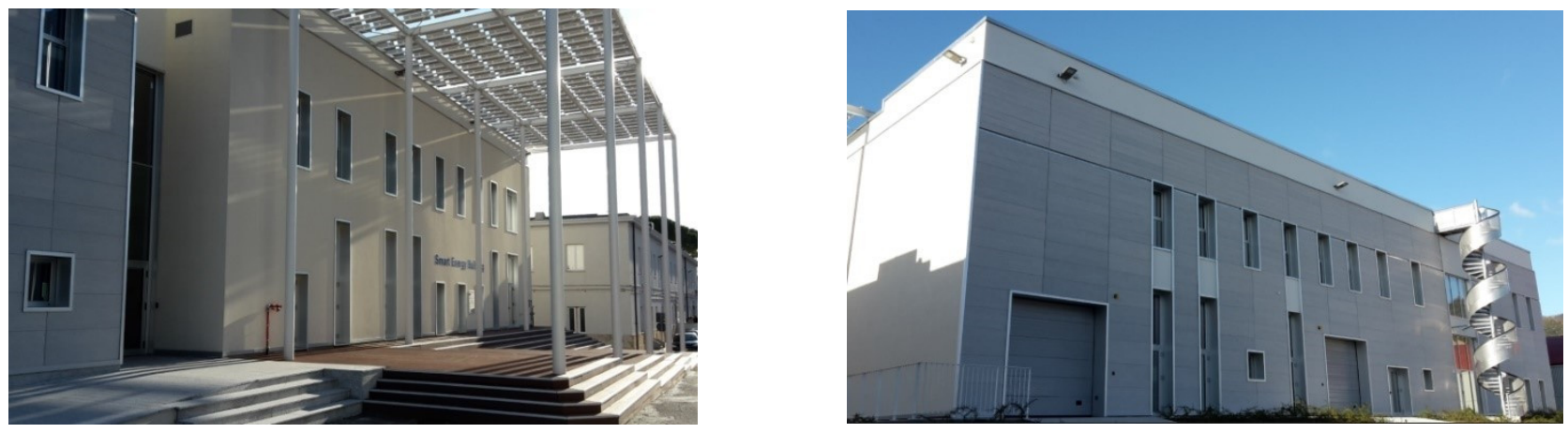

Figure 2. The Smart Energy Building (SEB). 


\subsection{Savona Campus 2.0: Upcoming Upgrade of the Technology Mix}

The Savona Campus is facing an upgrade of its technology mix. A project considering the introduction of new power plants and conversion units has been proposed, and in the upcoming months the installation will be finalized. The upgrade aims to increase the exploitation of renewable sources thanks to the introduction of two new rooftop photovoltaic fields of about $80 \mathrm{~kW}$ and $84 \mathrm{~kW}$ peak power. The introduction of these two new power plants makes the overall PV peak power of the Campus approximately $280 \mathrm{~kW}$. The expected electric energy production will be used to supply new reversible air/water heat pumps, for a total of $266 \mathrm{~kW}$ of added thermal power. The introduced heat pumps will be used to air condition several buildings of the Campus that do not have cooling systems, thus increasing the overall comfort of the users during the summer and reducing the thermal boiler dependences during the winter. Furthermore, a new CHP unit, consisting of a micro gas turbine of $100 \mathrm{~kW}$ of electrical rated power and $160 \mathrm{~kW}$ of thermal rated power, is going to be added to the mix to further reduce the dependency on natural gas thermal boilers. The considered upgrades are expected to result in an overall reduction of emissions and in an increase of self-consumption, leading towards a more energy self-sufficient Campus.

\subsection{The New SPEED2030 (Savona Positive Energy \& Environment District)}

The road towards the complete development of smart cities includes research based on small-scale real test cases. The accessibility and usability of operational data from public or private buildings is important to develop studies; however, such data are difficult to obtain due to the plurality of the subjects involved and the lack of suitable acquisition systems. From this point of view, university campuses offer ideal conditions for experimentation; during normal operation they can provide a significant amount of real data that is easily available and suitable for further investigation [36,42,43].

Although campuses are constantly subjected to changes and improvements, building layout, heating systems and main grid architectures cannot be easily modified, nor can the type of coupling with the external grid. For this reason, the possibility of adding new areas to existing ones plays a central role in exploring the performance of developing technologies. Planning new districts makes possible the testing of different configurations and consideration of the most recent developments in the legislative framework. Comparing the behavior of the new installations to existing ones helps researchers to find the best solutions while achieving a better understanding of the performance of the various technologies when applied to real buildings in the same geographical and climatic area.

In 2019, EU leaders established an agreement for achieving a climate-neutral EU by 2050. Climate neutrality is about emitting less and absorbing more; it means going beyond the concept of reducing greenhouse gas emissions as much as possible by additionally compensating for any remaining emissions. This is how a net-zero emissions balance can be achieved. All economic sectors must contribute to reduce greenhouse gas emissions; in modern residential, tertiary and commercial buildings it is possible to accomplish this goal by implementing the so-called "Positive Energy District". Positive Energy Districts (PEDs) are "energy-efficient and energy-flexible urban areas or groups of connected buildings which produce net zero greenhouse gas emissions and actively manage an annual local or regional surplus production of renewable energy" [44,45]. The PED framework is characterized by three main functions:

- Energy Efficiency Function (reduction of energy consumption);

- Energy Flexibility Function (active participation to increase the resilience and balancing of the regional energy system);

- Energy Production Function (increasing local renewable production and optimizing its use at a local level by advanced control systems and market opportunities).

The PED main target is to find optimal balance between energy efficiency, energy flexibility and local/regional energy production towards climate neutrality and energy surplus. 
Within this aforementioned framework, a study on the planned district near to the existing Savona Campus is presented here. The development of the area has been planned on the basis of the PED guidelines, focusing on the maximization of energy production from renewables and on the methods to better exploit the resources at the district level by using, where possible, microgrid configurations and energy sharing through REC (Renewable Energy Communities). The surplus of energy production can be shared over the boundaries of the district in the nearby residential area to progressively extend benefits from the PED to already existing portions of the city and to encourage the birth of new PEDs as well. Planning positive energy districts can attract public and private investment and promote the modernization of existing and obsolete infrastructures by increasing the level and quality of public services for citizens.

The available areas for the new SPEED2030 (Savona Positive Energy \& Environment District) are highlighted in yellow in Figure 3, while the boundaries of the Savona Campus are indicated with a red line. The new district was included in the municipal urban plan in 2011, with the aim of creating new accommodations for students and social housing, thereby taking advantage of the nearby university campus to encourage the birth of a new modern urban site. Many obstacles have prevented the exploitation of these areas in the past: the presence of a significant hydrogeological risk, the lack of public financial resources, the complexity of urban planning constraints, and an excess of bureaucracy that discouraged private investors. The main idea is to promote rational and conservative use of the territory by developing all the functions, with a limited impact on the ground.

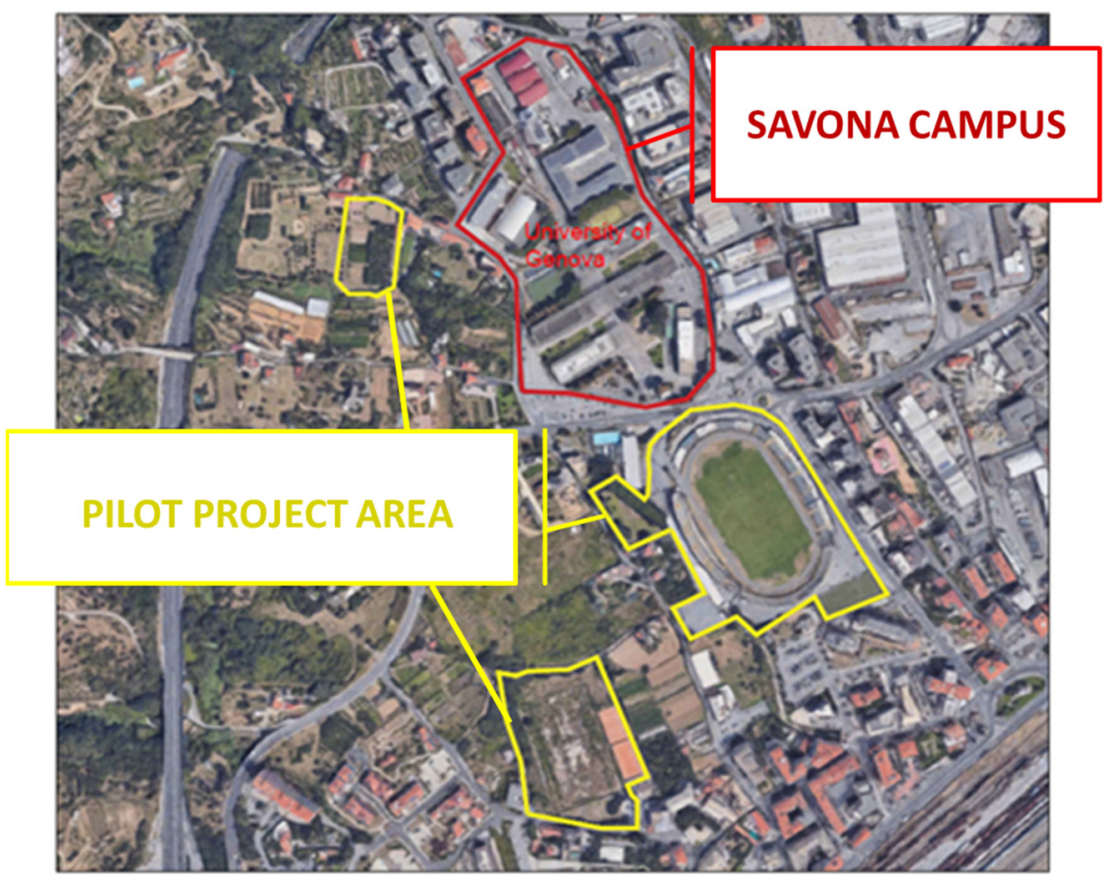

Figure 3. Available areas for the SPEED2030 project and the Savona Campus (University of Genoa).

The pilot project to be studied will be implemented in this new district, and the buildings will be located as shown in Figure 4. In particular, the district is made up of eight distinct main function areas, as follows:

1. $(1 \mathrm{a}, 1 \mathrm{~b})$ Public football stadium - main area (existing; subject to makeover);

2. $(2 \mathrm{a}, 2 \mathrm{~b}, 2 \mathrm{c}, 2 \mathrm{~d})$ Public football stadium-locker rooms, shops, workshops, grandstand (existing; subject to makeover) and Stadium Microgrid Control Center (SMCC) (planned);

3. (3) Public outdoor sports (existing; subject to renovation);

4. (4) University Microgrid Control Centre (UMCC) and related plants (storage, Hydrogen CHP, vehicle to grid) (planned);

5. (5) Student accommodation, university spaces (planned); 
6. (6) Social housing (planned);

7. (7) Public park (existing);

8. (8) Swimming pool (existing).

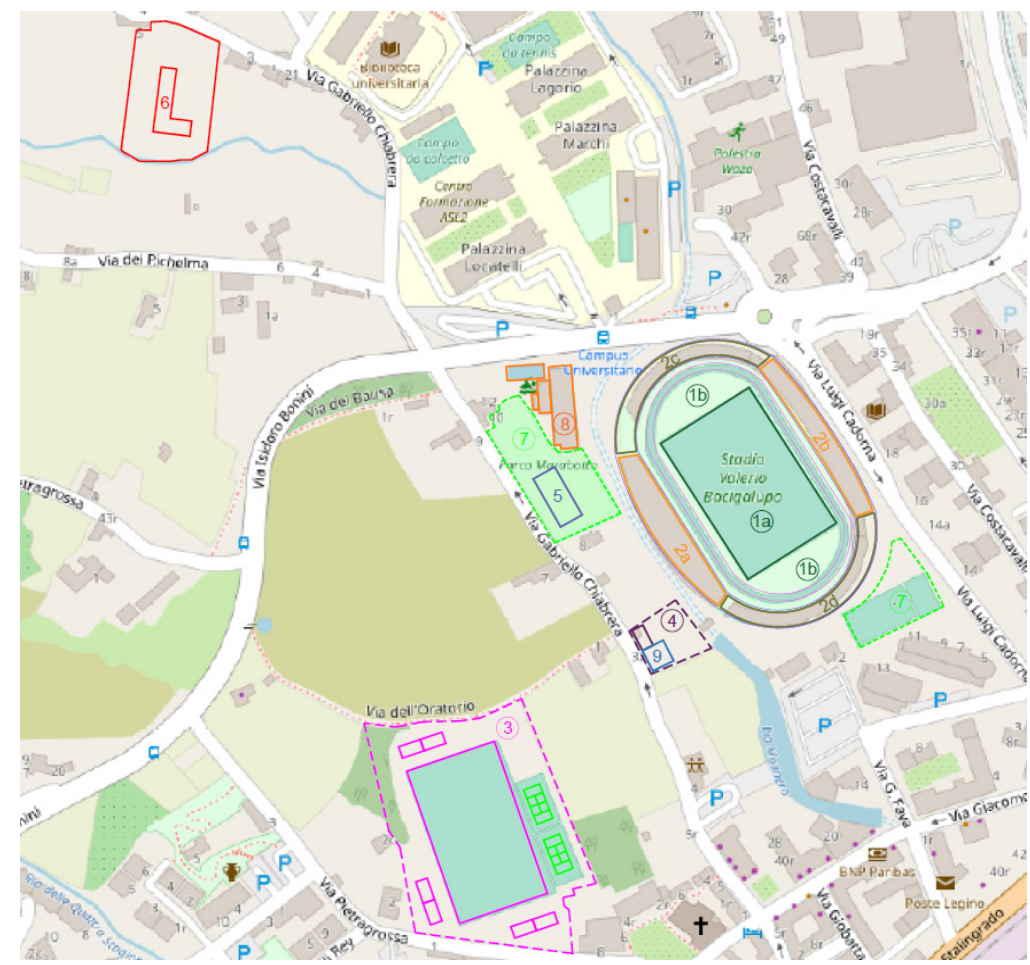

Figure 4. The areas of the SPEED2030 project.

From a technical point of view the main objectives of the pilot project are:

- testing the application of a sustainable power system in the framework of a local energy community;

- reaching a high degree of penetration of RES in a relevant portion of the urban territory, considering different types of buildings and different patterns of the final energy use;

- $\quad$ studying a carbon-free system integrating innovative technologies such as hydrogen CHP units, wind turbines and heat pumps.

Apart from the swimming pool, the establishments are owned either by the Municipality of Savona or the University of Genoa. The public football stadium needs a complete makeover; in this framework, the coverage of the grandstand can be used to install a photovoltaic power plant with a maximum size of about 1.47 MWp. The spaces under the stands could be used for the location of commercial activities and offices. The swimming pool is already heated with thermal power, provided by a CHP plant fed by natural gas, with rated electrical and thermal power equal to $25 \mathrm{kWe}$ and $57.6 \mathrm{kWt}$, respectively. New buildings for social housing, student accommodation, offices for the University and private companies can be located in a nearby area.

The significant amount of energy produced by the new main PV power plant could be shared among the users of the new district as actors of the new energy community. Moreover, all the buildings are planned to be equipped with PV plants as required by national legislation for new installations. The size of the aforementioned plants will be maximized through architectural integration of the PV modules. Any surplus energy will be used primarily to power local water treatment systems, waste management systems and electric vehicle charging, and will also be fed into the grid as a further benefit. Furthermore, the investigated solution also includes the installation of distributed electrical storage systems, to optimize the use of the electricity produced by the PV plants directly in each establishment and minimize the energy exchanged with the grid. 
The new buildings will be supplied with thermal and cooling energy produced by reversible electricity-driven heat pumps to completely avoid the use of gas. The domestic hot water will be produced mainly by thermal solar collectors coupled with thermal storage tanks. The considered heat pumps will be able to operate as backup units for domestic hot water production. Due to the large availability of renewable electrical energy from the main and the secondary PV power plants, it will be convenient to use induction plates for kitchen uses.

As part of the investigated pilot project, the aforementioned technologies will belong to two physical microgrids, which will be designed to provide a major part of the energy required by the district. The first one will be used to power the new university buildings (hereafter called "Mini-Campus" to distinguish it from the nearby main University Campus), the second will power the stadium and all the related services. Such a microgrid model has been developed to meet the technical requirements for the connection to the grid of different customers, in compliance with current regulations for connection to the grid.

A new building hosting the University Microgrid Control Center (UMCC) will be located near the student accommodation building. In the same area, the following plants are planned to be installed:

- 1 PV plant (installed on the roof of the Microgrid Control Building);

- 1 CHP plant fed by hydrogen and also used for research purposes;

- 1 electrical storage system;

- 1 vehicle-to-grid station (V2G station).

The production of hydrogen for supplying the CHP system will be guaranteed by an electrolyser, fed by the extraneous electricity production of the PV plants within the district. In addition, the possibility of supplying the electrolyser during the night with the power generated by nearby wind farms will be investigated, together with the optimal sizing of the hydrogen storage system. As previously mentioned, a second microgrid control centre (SMCC - Stadium Microgrid Control Center) will be located inside the stadium building to manage the related physical microgrid. The conceptual scheme of the whole pilot project is shown in Figure 5.

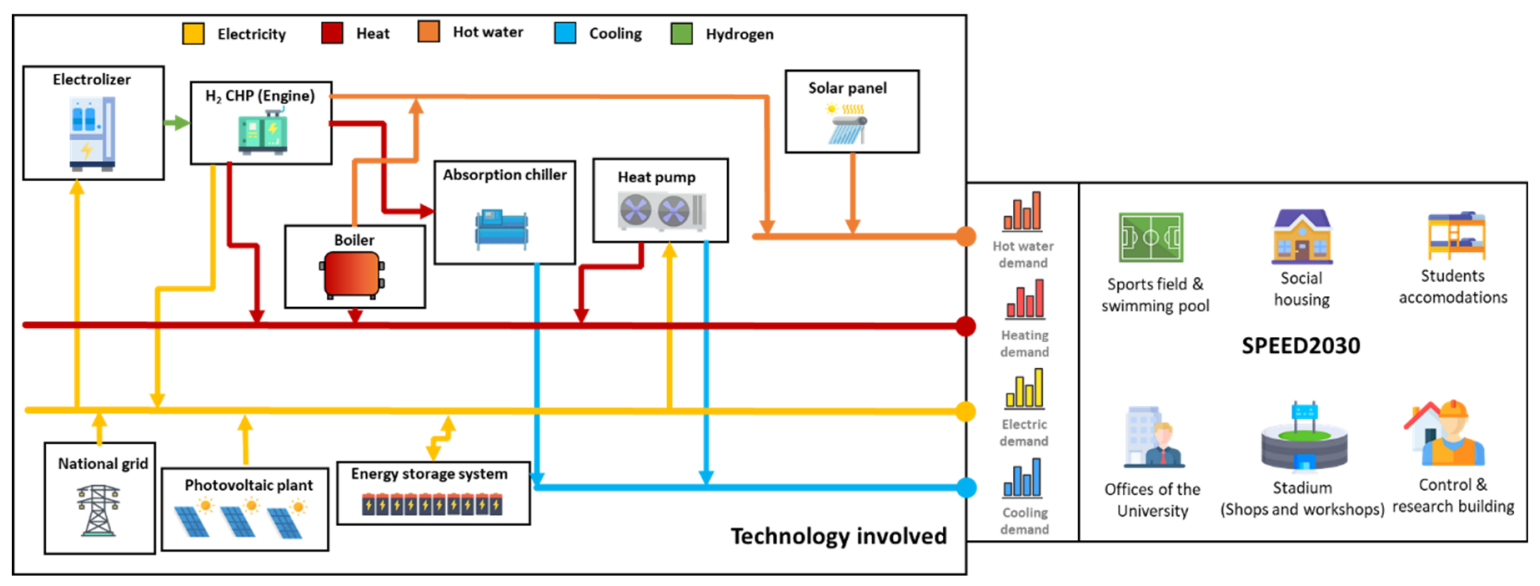

Figure 5. Pilot project-Energy flow scheme.

\section{Evaluation of KPIs for the Savona Campus, the Savona Campus 2.0 and the New Speed2030 District}

The new SPEED2030 District (currently in the design phase) is characterized by a set of power plants for self-production that are significantly different to those of the Savona Campus in the actual and the upcoming configurations. Table 1 summarizes the sizes of the plants present inside the Savona Campus and the new SPEED2030. The operating data of the Savona Campus in the actual configuration are provided by the SCADA of the SPM, while the data for the upcoming configuration refer to the delivered technical 
project. The data concerning SPEED2030 are collected from the preliminary project of the new energy district.

Table 1. Energy production plants inside Savona Campus and SPEED2030 District.

\begin{tabular}{cccc}
\hline & $\begin{array}{c}\text { Installed Power/Storage } \\
\text { Capacity } \\
\text { Savona Campus }\end{array}$ & $\begin{array}{c}\text { Installed Power/Storage Capacity } \\
\text { Savona Campus 2.0 }\end{array}$ & $\begin{array}{c}\text { Installed Power/Storage } \\
\text { Capacity } \\
\text { Speed2030 District }\end{array}$ \\
\hline \multirow{2}{*}{ Electricity } & $116 \mathrm{~kW}$ (PV plants) & $280 \mathrm{~kW}$ (PV plants) & $2029 \mathrm{~kW}$ (PV plants) \\
& $130 \mathrm{~kW}$ (Cogeneration units) & $230 \mathrm{~kW}$ (Cogeneration units) & $39 \mathrm{~kW}$ (Cogeneration units) \\
& $900 \mathrm{~kW}$ (Boilers) & $900 \mathrm{~kW}$ (Boilers) & $442 \mathrm{~kW}$ (Boilers) \\
Thermal energy & $224 \mathrm{~kW}$ (Thermal & $384 \mathrm{~kW}$ (Thermal & $96 \mathrm{~kW}$ (Thermal \\
& power-cogeneration units) & power-cogeneration units) & power-cogeneration units) \\
& power-absorption chillers) & $220 \mathrm{~kW}$ (Cooling & $692 \mathrm{~kW}$ (Thermal \\
Storage & $45 \mathrm{~kW}$ (Thermal & power-absorption chillers) & power-heat pumps) \\
& power-geothermal heat pump) & $311 \mathrm{~kW}$ (Thermal & power-heat pumps) \\
& $140 \mathrm{kWh}$ & $140 \mathrm{kWh}$ & $6390 \mathrm{kWh}$ \\
\hline
\end{tabular}

A comparison of the three different cases through the application of the proposed KPI approach is presented here. In particular, in Figure 6, only the energy-based KPIs are shown, using spider diagrams, while the emissions-based KPIs are depicted in Figure 7. It is possible to highlight how, for the Savona Campus, in the actual configuration, the electrical energy demand depends mainly on electricity supplied by the national grid, since its ESP value is equal to $34 \%$. The electricity self-production is currently based on fossil fuels, since $70 \%$ of the locally produced electricity comes from the natural gas CHP units (ESPCHP); the thermal energy is supplied by CHP units for $45 \%$ (TCHP) and by boilers for $53 \%$ (TB). Only $30 \%$ of the electrical energy (ESPRES) and $2 \%$ of the thermal energy (TRES) is produced by means of RES. On the other hand, in the upcoming configuration, the ESP value increases to $56 \%$ thanks to the added installed power coming from PV plants and the CHP unit. The electricity self-production is expected to be less, based on fossil fuels, since ESPCHP is decreased to $60 \%$ and ESPRES is increased to $40 \%$. Moreover, the massive introduction of heat pumps is expected to reduce the dependence on thermal boilers, which can be noted in the TB, which sees a decrease to $19 \%$; the THP, which increases up to $21 \%$; and the TRES, which reaches $17 \%$. The new scenario is characterized by a more balanced contribution from the CHP units and an increased role for renewable sources. For the SPEED2030 District, the electrical load is completely fulfilled by means of selfproduced energy; thus, its ESP value is very high, around 103\%. Instead, the SPEED2030's self-produced energy is mostly generated by the exploitation of RES: its ESPRES and TRES indicators are respectively equal to $92 \%$ and $39 \%$, whereas only $8 \%$ of the electrical production comes from the CHP units (ESPCHP). 

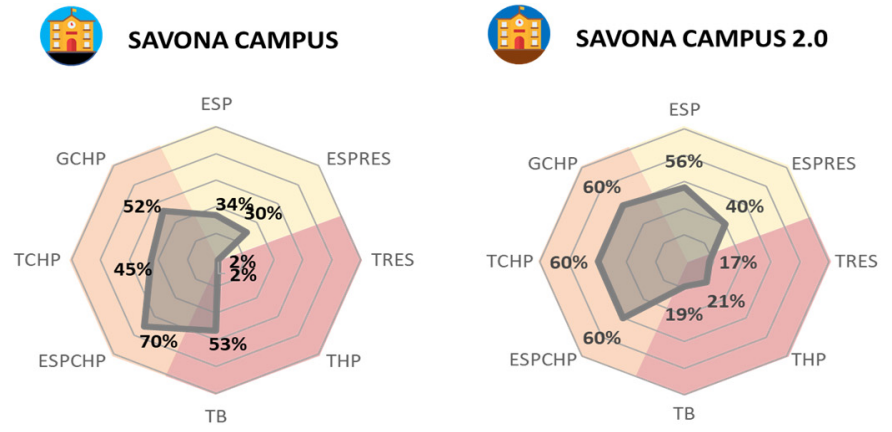

\section{SPEED2030 - PILOT PROJECT}

Figure 6. Energy-based KPIs.
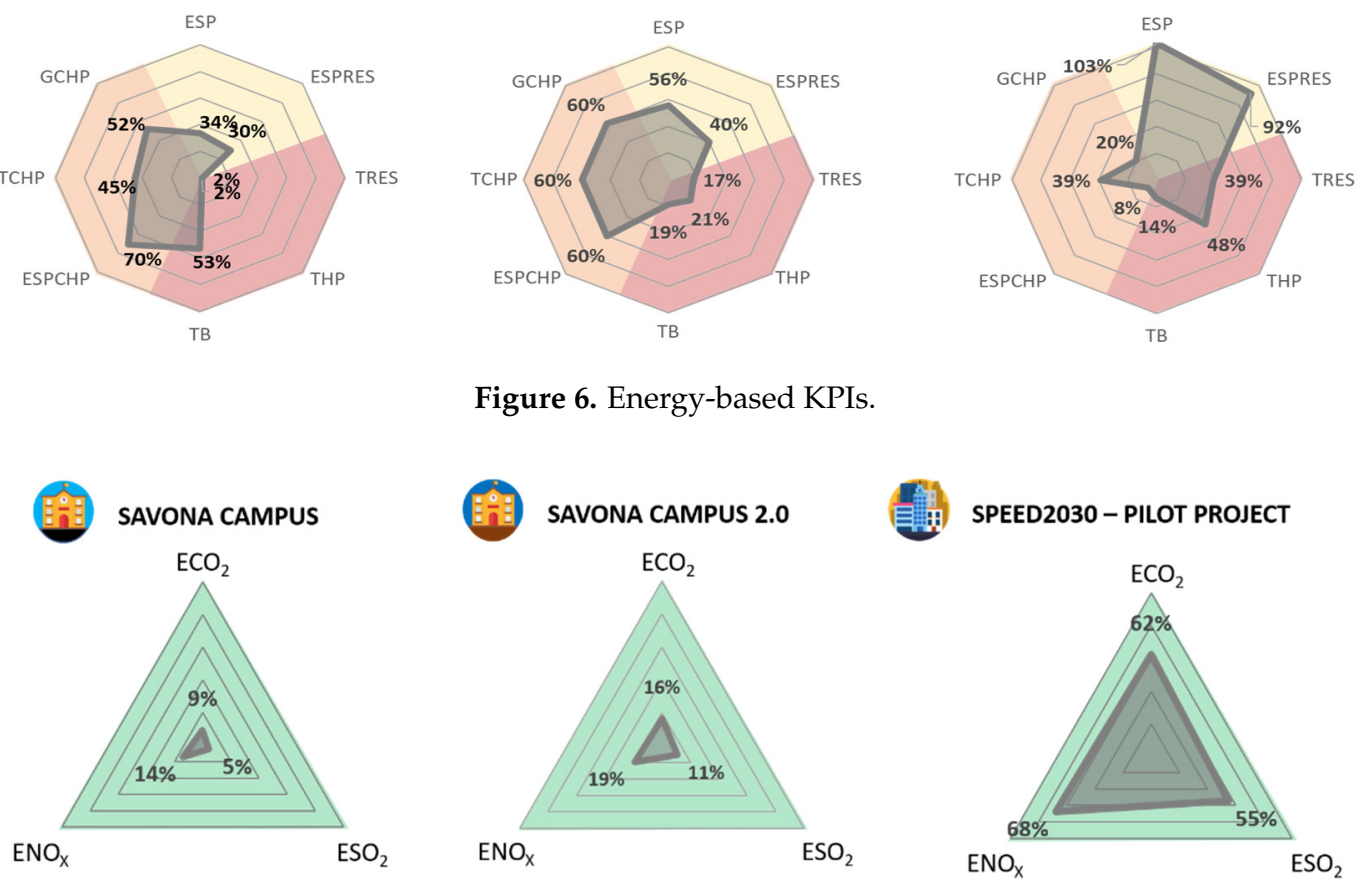

Figure 7. Environmental KPIs.

The technology mix adopted in the three examined cases heavily affects the environmental performance, as can be seen in Figure 7; the avoided emissions with respect to those associated with an equivalent site supplied by traditional energy sources are presented for each case. The Savona Campus in the actual configuration has a modest impact with respect to the AS-IS scenario due to a heavy dependence on technologies supplied by natural gas. The $\mathrm{ECO}_{2}$ is equal to $9 \%$, the $\mathrm{ENO}_{\mathrm{x}}$ is a little higher, equal to $14 \%$ and the $\mathrm{ESO}_{2}$ has a lower value, equal to $5 \%$. This can be explained by considering a lower absorption of the electricity provided by the national grid and a concurrent reduction of thermal energy supplied by thermal boilers thanks to the $\mathrm{CHP}$ units working in cogeneration mode. Moreover, the presence of renewable generation units (PV) further reduces emissions, affecting $\mathrm{SO}_{2}$ in particular. The Savona Campus in the upcoming configuration is expected to see an overall improvement of the environmental $\mathrm{KPIs}$. $\mathrm{ECO}_{2}$ is equal to $16 \%, \mathrm{ENO}_{\mathrm{x}}$ stands at $19 \%$ and $\mathrm{ESO}_{2}$ amounts to $11 \%$, thanks to a substantial increase in photovoltaic production and a massive introduction of heat pumps. For SPEED2030, the change in the design approach is evident from Figure 7, where significant impacts on the avoided emissions due to the higher use of renewable energy sources is highlighted for both the electric and thermal demand supply. The $\mathrm{ECO}_{2}$ is equal to almost $62 \%$, the $\mathrm{ENO}_{\mathrm{x}}$ stands at $68 \%$ and the $\mathrm{ESO}_{2}$ is around $55 \%$.

\section{Conclusions}

The present work deals with the realization of microgrids, energy communities and positive energy districts and examines several real cases. Due to the large investment and operating costs involved in such projects, at the preliminary design phase it is necessary to evaluate the best technologies for use in these projects and then quantify their optimal size. While the size of the technologies can be decided by using, for example, optimal planning studies, the choice of one technology over another can be made with reference to different and wider criteria. In this paper, several KPIs are adopted to drive the choice of the technologies for new projects by comparing them with existing ones. The comparison of the KPIs for the Savona Campus in the actual and upcoming configurations and the new district SPEED2030 highlights that the two smart districts have common features, but also 
substantial differences. Although both the sites are strongly oriented toward the use of self-generated energy, the Savona Campus is still deeply tied to fossil fuel production (CHP and boilers), while SPEED2030 bases its production almost entirely on renewable energy sources. The Savona Campus, realized in 2014, was designed to implement and study the integration of Distributed Generation within an urban district, whereas SPEED2030, which could be qualified as a "Positive Energy District", is planned to reach the new goals in terms of emission and energy generation. The presented KPI-based approach has the advantage of being able to compare different energy sites, whether they are already realized, are upcoming or are at the planning stage, to identify their main features from the available data, including from preliminary project materials. This proposed methodology is a useful tool in order to understand whether the designed sites are well planned and whether they will achieve the planned goals in terms of energy generation and emission.

Author Contributions: Conceptualization, S.B., B.B. and F.D.; methodology, S.B., B.B., G.B. and G.P.; writing, S.B., G.B., B.B., P.L. and G.P.; analysis of results, S.B., B.B., G.B. and G.P.; final review, S.B. and F.D. All authors have read and agreed to the published version of the manuscript.

Funding: This research was funded by ALPGRIDS project, contract agreement $\mathrm{n}$. 843 (www.alpinespace.eu/alpgrids accessed on 4 August 2021).

Conflicts of Interest: The authors declare no conflict of interest.

\section{References}

1. The Sustainable Development Agenda. Available online: https://www.un.org/sustainabledevelopment/development-agenda/ (accessed on 24 December 2020).

2. Jarillo, M.P.; Pedraza, L.; Ger, P.M.; Bocos, E. Challenges of online higher education in the face of the Sustainability Objectives of the United Nations: Carbon footprint, accessibility and social inclusion. Sustainability 2019, 11, 5580. [CrossRef]

3. Mora, H.; Pujol-López, F.A.; Mendoza-Tello, J.C.; Morales-Morales, M.R. An education-based approach for enabling the sustainable development gear. Comput. Hum. Behav. 2018, 107, 105775. [CrossRef]

4. Gallo, M.; Marotta, V.; Magrassi, F.; Taramasso, A.C.; Del Borghi, A. University campus waste prevention and reduction: A circular-economy approach. Econ. Policy Energy Environ. 2017, 2017, 235-252. [CrossRef]

5. Chu, S.; Cui, Y.; Liu, S.C.N. The path towards sustainable energy. Nat. Mater. 2016, 16, 16-22. [CrossRef]

6. Chen, B.; Xiong, R.; Li, H.; Sun, Q.; Yang, J. Pathways for sustainable energy transition. J. Clean. Prod. 2019, 228, 1564-1571. [CrossRef]

7. A European Green Deal. Available online: https://ec.europa.eu/info/strategy/priorities-2019-2024/european-green-deal_en (accessed on 5 January 2021).

8. Sources of Greenhouse Gas Emissions (United States Environmental Protection Agency). Available online: https: / www.epa. gov / ghgemissions/sources-greenhouse-gas-emissions (accessed on 24 December 2020).

9. Lasseter, R.; Akhil, A.; Marnay, C.; Stephens, J.; Dagle, J.; Guttromsom, R.; Meliopoulos, A.P.; Yinger, R.; Eto, J. Integration of Distributed Energy Resources. The CERTS Microgrid Concept; Technical Report; U.S. Department of Energy: Berkeley, CA, USA, 2002. [CrossRef]

10. Ahmadi, M.; Rosenberger, J.M.; Lee, W.-J.; Kulvanitchaiyanunt, A. Optimizing load control in a collaborative residential microgrid environment. IEEE Trans. Smart Grid 2015, 6, 1196-1207. [CrossRef]

11. Casini, M.; Zanvettor, G.G.; Kovjanic, M.; Vicino, A. Optimal energy management and control of an industrial microgrid with plug-in electric vehicles. IEEE Access 2019, 7, 101729-101740. [CrossRef]

12. Hossain, E.; Kabalci, E.; Bayindir, R.; Perez, R. Microgrid testbeds around the world: State of art. Energy Convers. Manag. 2014, 86, 132-153. [CrossRef]

13. Lu, X.; Bahramirad, S.; Wang, J.; Chen, C. Bronzeville community microgrids: A reliable, resilient and sustainable solution for integrated energy management with distribution systems. Electr. J. 2015, 28, 29-42. [CrossRef]

14. Cornélusse, B.; Savelli, I.; Paoletti, S.; Giannitrapani, A.; Vicino, A. A community microgrid architecture with an internal local market. Appl. Energy 2019, 242, 547-560. [CrossRef]

15. Junior, R.M.; Fien, J.; Horne, R. Implementing the UN SDGs in Universities: Challenges, opportunities, and lessons learned. Sustain. J. Rec. 2019, 12, 129-133. [CrossRef]

16. Salvioni, D.M.; Franzoni, S.; Cassano, R. Sustainability in the Higher Education System: An opportunity to improve quality and image. Sustainability 2017, 9, 914. [CrossRef]

17. El-Jardali, F.; Ataya, N.; Fadlallah, R. Changing roles of universities in the era of SDGs: Rising up to the global challenge through institutionalising partnerships with governments and communities. Health Res. Policy Syst. 2018, 16, 38. [CrossRef]

18. Filho, W.L.; Wu, Y.-C.J.; Brandli, L.L.; Avila, L.V.; Azeiteiro, U.M.; Caeiro, S.; Madruga, L.R.d.R.G. Identifying and overcoming obstacles to the implementation of sustainable development at universities. J. Integr. Environ. Sci. 2017, 14, 93-108. [CrossRef] 
19. Miotto, G.; Blanco González, A.; Del Castillo, F.C. Social responsibility: A tool for legitimation in Spanish Universities' strategic plans. Trípodos 2018, 42, 59-79.

20. Giordano, V.; Vitiello, S.; Vasiljevska, J. Definition of an Assessment Framewok for Projects of Common Interest in the Field of Smart Grids; JRC Report; Publications Office of the European Union: Luxembourg, 2014.

21. Walnum, H.T.; Hauge, L.; Lindberg, K.B.; Mysen, M.; Nielsen, B.F.; Sørnes, K. Developing a scenario calculator for smart energy communities in Norway: Identifying gaps between vision and practice. Sustain. Cities Soc. 2019, 46, 101418. [CrossRef]

22. Chan, D.; Cameron, M.; Yoon, Y. Implementation of micro energy grid: A case study of a sustainable community in China. Energy Build. 2017, 139, 719-731. [CrossRef]

23. Personal, E.; Guerrero, J.I.; Garcia, A.; Peña, M.; Leon, C. Key performance indicators: A useful tool to assess smart grid goals. Energy 2014, 76, 976-988. [CrossRef]

24. Cielo, A.; Margiaria, P.; Lazzeroni, P.; Mariuzzo, I.; Repetto, M. Renewable Energy Communities business models under the 2020 Italian regulation. J. Clean. Prod. 2021, 316, 128217. [CrossRef]

25. Li, Y.; O’Donnell, J.; García-Castro, R.; Vega-Sánchez, S. Identifying stakeholders and key performance indicators for district and building energy performance analysis. Energy Build. 2017, 155, 1-15. [CrossRef]

26. Alrashed, S. Key performance indicators for smart campus and microgrid. Sustain. Cities Soc. 2020, 60, 102264. [CrossRef]

27. Sintef \& NTNU. Zero Emission Neighborhoods in Smart Cities (ZEN). no. 7. 2018. Norway. Available online: https:/ fmezen.no (accessed on 24 December 2020).

28. Angelakoglou, K.; Nikolopoulos, N.; Giourka, P.; Svensson, I.-L.; Tsarchopoulos, P.; Tryferidis, A.; Tzovaras, D. A methodological framework for the selection of key performance indicators to assess smart city solutions. Smart Cities 2019, 2, 269-306. [CrossRef]

29. Picioroaga, I.I.; Eremia, M.; Sanduleac, M. Smart City: Definition and evaluation of Key Performance Indicators. In Proceedings of the 2018 International Conference and Exposition on Electrical and Power Engineering (EPE), Iasi, Romania, 18-19 October 2018; pp. 217-222.

30. Pramangioulis, D.; Atsonios, K.; Nikolopoulos, N.; Rakopoulos, D.; Grammelis, P.; Kakaras, E. A Methodology for determination and definition of key performance indicators for smart grids development in island energy systems. Energies 2019, 12, 242. [CrossRef]

31. Tur, M.R.; Bayindir, R. Project surveys for determining and defining key performance indicators in the development of smart grids in energy systems. Int. J. Smart Grid 2019, 3, 2.

32. Moretti, M.; Djomo, S.N.; Azadi, H.; May, K.; De Vos, K.; Van Passel, S.; Witters, N. A systematic review of environmental and economic impacts of smart grids. Renew. Sustain. Energy Rev. 2017, 68, 888-898. [CrossRef]

33. Cuesta, M.A.; Castillo-Calzadilla, T.; Borges, C. A critical analysis on hybrid renewable energy modeling tools: An emerging opportunity to include social indicators to optimise systems in small communities. Renew. Sustain. Energy Rev. 2020, $122,109691$. [CrossRef]

34. Savona Campus. Available online: https://www.campus-savona.it/en/ (accessed on 4 August 2021).

35. ALPGRIDS Project. Available online: https://www.alpine-space.eu/projects/alpgrids/en/home (accessed on 5 January 2021).

36. Delfino, F.; Procopio, R.; Rossi, M.; Bracco, S.; Brignone, M.; Robba, M. Microgrid Design and Operation: Toward Smart Energy in Cities; Artech House: Boston, MA, USA, 2018; ISBN 9781630811501.

37. Magrassi, F.; Del Borghi, A.; Gallo, M.; Strazza, C.; Robba, M. Optimal planning of sustainable buildings: Integration of Life Cycle Assessment and optimization in a Decision Support System (DSS). Energies 2016, 9, 490. [CrossRef]

38. Bianco, G.; Bracco, S.; Delfino, F.; Gambelli, L.; Robba, M.; Rossi, M. A building energy management system based on an equivalent electric circuit model. Energies 2020, 13, 1689. [CrossRef]

39. Bracco, S.; Delfino, F.; Ferro, G.; Pagnini, L.; Robba, M.; Rossi, M. Energy planning of sustainable districts: Towards the exploitation of small size intermittent renewables in urban areas. Appl. Energy 2018, 228, 2288-2297. [CrossRef]

40. Bracco, S.; Delfino, F.; Pampararo, F.; Robba, M.; Rossi, M. Planning and management of sustainable microgrids: The test-bed facilities at the University of Genoa. In Proceedings of the IEEE Africon 2013 Conference, Pointe-Aux-Piments, Mauritius, 9-12 September 2013.

41. Bracco, S.; Delfino, F.; Piazza, G. E-Mobility Microgrid Laboratory at the Savona Campus of Genova University. In Proceedings of the 12th AEIT International Annual Conference, AEIT 2020, Catania, Italy, 23-25 September 2020.

42. Bracco, S.; Delfino, F.; Laiolo, P.; Morini, A. Planning \& Open-Air Demonstrating Smart City Sustainable Districts. Sustainability 2018, 10, 4636. [CrossRef]

43. Brenna, M.; Foiadelli, F.; Longo, M.; Bracco, S.; Delfino, F. Smart microgrids in smart campuses with electric vehicles and storage systems: Analysis of possible operating scenarios. In Proceedings of the 2016 IEEE International Smart Cities Conference (ISC2), Trento, Italy, 12-15 September 2016.

44. Bossi, S.; Gollner, C.; Theierling, S. Towards 100 Positive Energy Districts in Europe: Preliminary data analysis of 61 European cases. Energies 2020, 13, 6083. [CrossRef]

45. Gollner, C.; Hinterberger, R.; Bossi, S.; Theierling, S.; Noll, M.; Meyer, S.; Schwarz, H.G. Europe towards Positive Energy Districts_First Update. 2020. Available online: https://jpi-urbaneurope.eu/wp-content/uploads/2020/06/PED-BookletUpdate-Feb-2020_2.pdf (accessed on 4 August 2021). 